\title{
Parent of Origin and Prognosis in Familial Breast Cancer in Sweden
}

\author{
CAMILLA WENDT ${ }^{1,2}$, ANNIKA LINDBLOM ${ }^{3,4}$, BRITA ARVER ${ }^{1,5}$, \\ ANNA VON WACHENFELDT ${ }^{1,2}$ and SARA MARGOLIN ${ }^{1,2}$ \\ ${ }^{1}$ Departments of Oncology-Pathology and ${ }^{3}$ Molecular Medicine and Surgery, \\ Karolinska Institute Solna, Stockholm, Sweden; \\ ${ }^{2}$ Department of Oncology, Sodersjukhuset, Stockholm, Sweden; \\ ${ }^{4}$ Departments of Clinical Genetics and ${ }^{5}$ Oncology, Karolinska University Hospital Solna, Stockholm, Sweden
}

\begin{abstract}
Background: It has been suggested that prognosis in familial breast cancer could be influenced by the parent of origin, with a worse prognosis when inherited paternally. This study aimed to investigate the effect of the parent of origin on prognosis. Patients and Methods: Index patients were divided into two study groups depending on the parent of origin. Tumour characteristics and survival data for index patients were collected. Results: In total, 319 families fulfilled the inclusion criteria. No significant difference in overall or recurrence-free survival between those with maternal and those with paternal inheritance was observed, with hazard ratios (HR) of 0.99 (95\% confidence interval $(C I)=0.54$ to $1.80, p=0.97)$ and $1.22(95 \% C I=0.78$ to $1.92, p=0.38)$, respectively. Conclusion: We found no evidence for a worse prognosis in patients with paternally inherited breast cancer. However, only large differences in prognosis were excluded and the tendency for worse recurrence-free survival in the group with paternal inheritance therefore merits further study.
\end{abstract}

Breast cancer is the most common cancer in women worldwide and its incidence is increasing. The prognosis of breast cancer is affected by several risk factors such as tumour size and grade, lymph node status, oestrogen receptor (ER) status and human epidermal growth factor 2 status. Furthermore, the outcome is influenced by adjuvant treatment. Several studies have investigated a putative inherited component with impact on prognosis. In a retrospective unselected cohort of 1,975 patients with breast

Correspondence to: Camilla Wendt, MD, Department of Oncology, Sodersjukhuset, S-118 83, Stockholm, Sweden. Tel +46 86161000, e-mail: camilla.wendt@sll.se

Key Words: Breast cancer, inheritance, prognosis, genomic imprinting. cancer in Sweden, family history was studied. Affected women with a family history were divided into study groups depending on inheritance. The results showed an increasing predominance of maternally inherited cases over time, suggesting a worse prognosis when breast cancer is inherited paternally (1). The effect of the parent of origin in inheritance on prognosis was suggested as one possible explanation, as well as shared tumour or treatment characteristics and lifestyle/environmental factors. Parent-oforigin effects are frequently considered synonymous with genomic imprinting, a process where either the paternal or the maternal allele is epigenetically silenced. This epigenetic phenomenon might contribute to the development and progression of cancer and the tumour phenotype is thereby dependent on from which parent the causal allele is inherited (2). Imprinted regions in invasive breast cancer have been associated with negative hormonal receptor status, a prognostic factor for poor breast cancer prognosis (3). Furthermore, the imprinting status of insulin-like growth factor 2 has been associated with a more aggressive triplenegative breast cancer phenotype (4).

In addition to imprinting, other genetic risk factors may also have an impact on prognosis. Carrying the moderate breast cancer susceptibility gene checkpoint kinase 2 (CHEK2) 1100delC has been associated with poor prognosis (5). In a study of breast cancer prognosis in familial breast cancer, the prognosis was concordant in close relatives. Daughters and sisters of probands with poor prognosis had significantly higher breast cancer mortality compared to the corresponding group with good prognosis (6). The results were reproduced in a similar study, even after adjustment for established prognostic factors and treatment (7).

The aim of the present study was to test the hypothesis of a parent-of-origin effect on prognosis in hereditary breast cancer. We used a cohort of familial breast cancer families from Stockholm County. All families had been previously tested negative for high-risk predisposition genes. Index patients were 
divided into two study arms depending on whether breast cancer was maternally or paternally derived. We collected tumour characteristics and survival data through medical records.

\section{Patients and Methods}

The study cohort consisted of all 1,364 families counselled for familial breast cancer and which tested negative for predisposing high penetrance genes in the Stockholm County between February 2000 and January 2012. The probands were either referred to or self-referred to one of the three oncogenetic clinics in Stockholm. In the counselling process, the majority of the breast cancer diagnoses in the families were verified through medical records, the Swedish Cancer Registry or death certificates. Each family had screened negative for predisposing mutations in the breast cancer susceptibility genes 1 and 2 (BRCA1 and $B R C A 2$ ). Other high-risk genes were tested only if the individual pedigree indicated a specific breast cancer syndrome. All genetic testing was performed at the same laboratory at the Department of Oncology at Lund University Hospital. For BRCA mutation analysis, denaturing highperformance liquid chromatography (DHPLC) was used as the screening tool between 2000 and 2005. In addition to DHPLC, from 2006 to 2010, multiple ligation-dependent probe amplification (MLPA) was performed to exclude larger genomic rearrangements. Together, DHPLC and MLPA have a stated sensitivity of $95 \%$. For cases before 2006 , blood samples were reanalysed using MLPA when the technique was introduced. For samples from 2010 and later, analysis was performed using nextgeneration sequencing, with a sensitivity of over $95 \%$. To increase the study sample size, a population-based cohort from southern Stockholm with 487 affected women was added. Family history of cancer had been obtained through a questionnaire. In this cohort, collected from October 1998 to April 2000, pathogenic BRCA1 mutations were excluded as a part of the study design, moreover, the women were offered counselling and adequate additional screening outside the study with the same routines and at same laboratory as for the main study cohort.

All pedigrees from the mutation-negative families were evaluated and included if they contained two or more cases of breast cancer in first- or second degree relatives, or first cousins. Likewise, index patients from the population-based cohort were included if they fulfilled the same inclusion criteria. To avoid over-representation of families ascertained on account of the mother being affected, parents of the index case were not counted. Probands previously affected by breast cancer were regarded as the index case, otherwise an index case from the youngest generation in the families was chosen. The familial cohort consisted of all screened BRCA-negative families from 2000 to 2012, but since many probands sought counselling a long time after they received their breast cancer diagnosis, the inclusion date (date of diagnosis) may be before the year 2000. The index cases were divided into two study arms, paternal or maternal inheritance. Families with cases of breast cancer in both family branches were excluded. Tumour characteristics and survival data were collected for the index patient.

Recurrence-free survival time was calculated from the date of diagnosis to the date of locoregional recurrence, of distant recurrence or of death, whichever came first. For patients alive and recurrence-free, the time was calculated from the date of diagnosis to the date of last clinical check-up or the date of the most recent contact with healthcare services.
Overall survival was calculated from the date of diagnosis to the date of death, or for patients still alive to the date of last clinical check-up or contact with healthcare services. The median follow-up time was estimated using the reversed Kaplan-Meier technique. Survival over time was estimated using the Kaplan-Meier technique with the number of patients still at risk included in the graphs. Proportional hazards regression was used to estimate the univariate and multivariate effect of the different variables on survival time. Results are presented as hazard ratios (HRs) together with $95 \%$ confidence intervals (CI). All reported $p$-values are two-sided and refer to Wald tests.

\section{Results}

We analysed overall and recurrence-free survival in the index patients of the two study groups with either maternal or paternal inheritance. Out of the $348 B R C A$-negative families who met inclusion criteria, index patients from 319 families were included in the study (Figure 1). Medical charts were not available for 24 patients, mainly because the index patients had moved from Stockholm County. To obtain a well-defined cohort, five index patients who were diagnosed before 1990 were not included.

The mean age was 50.5 years (range $=27-84$ years) in the maternal inheritance group and 47.9 years (range $=25-82$ years) in the paternal inheritance group. Tumour characteristics in the study cohort were representative of the general breast cancer population in Sweden. Nodal status was positive in 35\% (108/306, missing data in 13) and ER status was positive in $73 \%$ of the patients $(180 / 248$, missing data in 71$)$. ER status did not influence the effect of inheritance on overall and recurrence-free survival, but was not otherwise included in the multivariate analysis due to the high amount of missing data (Tables I and II). The median follow-up time was 11 years.

No significant difference in overall or recurrence-free survival between maternal and paternal inheritance of breast cancer was observed, with HRs of 0.99 (95\% CI $=0.54$ to $1.80)$ and $1.22(95 \% \mathrm{CI}=0.78$ to 1.92$)$ respectively (Table I and II, Figures 2 and 3).

\section{Discussion}

Our result does not support the previous findings of a worse prognosis when breast cancer is paternally inherited. However, the sample size allowed us only to detect major differences in prognosis and the tendency for worse recurrence-free survival with paternally transferred disease merits further study in a larger cohort $(\mathrm{HR}=1.22,95 \%$ $\mathrm{CI}=0.78$ to 1.92 ) (Table II, Figure 3 ). This is a follow-up study of the results of Lindblom et al. which indicated a marked difference in prognosis (1). A large difference in the number of maternal and paternal inherited cases were found where maternally transmitted disease dominated and the discrepancy increased over time. More efficient adjuvant 


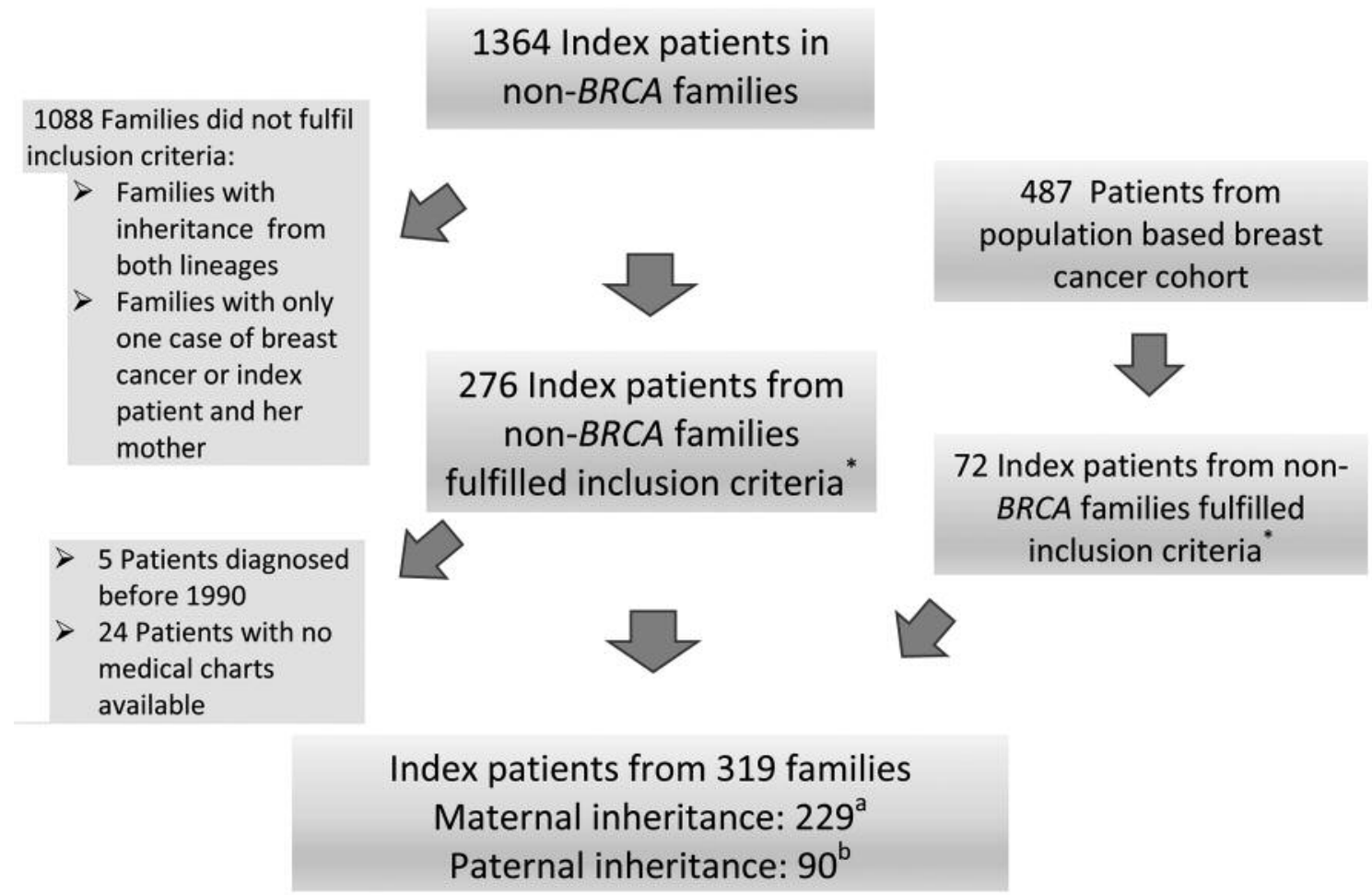

Figure 1. Flowchart illustrating inclusion and exclusion of study families. Inclusion criteria: Families with index patient and at least one first- or second-degree relative or first cousin (mothers not counted) affected by breast cancer. ${ }^{a} A$ total of 181 patients from the hereditary breast cancer cohort and 48 patients from the population-based cohort. ${ }^{b} A$ total of 66 patients from the hereditary breast cancer cohort and 24 patients from the population-based cohort. BRCA: Breast cancer susceptibility genes 1 and 2.

therapy in the present study could be part of the explanation for this. In recent years, a more subtle impact of parental origin in complex disease has been suggested. Commonly imprinted loci may be components of the genetic background in several complex traits (8). Kong et al. identified five lowrisk loci in two genomic regions harbouring imprinted genes, with parent-of-origin-specific association with cancer and diabetes, implicating the role of imprinting in complex disease (9). Since most studies do not differentiate between maternal and paternal alleles, little is known about the number and effect of imprinted genes. In another study in an unselected breast cancer cohort, the predominance of maternal inheritance was reported and the authors suggested that maternal genetic effects such as imprinting influence the risk of being affected (10).

This study was performed on a cohort with strong family history; almost half of the index patients had two or more affected close relatives. In general, as part of the counselling procedure, histological verification is obtained for all breast cancer diagnoses in close relatives. To achieve a well-defined study group, we used a BRCA-negative cohort. In the previous study of Lindblom et al., breast cancer families originated from an unselected non-screened cohort and further studies on that same cohort revealed that there were a few $B R C A$-positive cases among the families, hence it is unlikely that $B R C A$ mutation status explains the difference in prognosis $(11,12)$. Tumour and patient characteristics of the cohort reflect unselected patients with breast cancer in Sweden, except for younger age at diagnosis. Lower age at onset is expected since it is a marker of familial breast cancer and a criterion for genetic screening of the breast cancer genes BRCAI and BRCA2. The missing data for ER status (22\%) are unlikely to bias the result.

There are, however, limitations to our study that may have affected our findings. Even though affected mothers were not counted as cases when including patients, the distribution was asymmetric, with more than twice as many cases with maternally derived disease compared to paternal transmission. This is a plausible consequence of increased awareness of inherited breast cancer and greater accuracy in self-reported family history in women with maternal lineage. It is uncertain whether the skewed distribution of patients affects the result. The difference was almost as great in index patients from the unselected cohort, indicating that women with paternal inheritance have less knowledge of family history of breast cancer. A minor part of the asymmetry 
Table I. Overall survival according to prognostic factors.

\begin{tabular}{|c|c|c|c|c|c|}
\hline \multirow[b]{2}{*}{ Factor } & \multirow[b]{2}{*}{ Events/patients } & \multicolumn{2}{|c|}{ Univariate analysis } & \multicolumn{2}{|c|}{ Multivariate analysis ${ }^{\dagger}$} \\
\hline & & $\mathrm{HR}(95 \% \mathrm{CI})$ & $p$-Value & HR $(95 \%$ CI) & $p$-Value \\
\hline \multicolumn{6}{|l|}{ Age } \\
\hline$<50$ years & $26 / 168$ & 1 & & 1 & \\
\hline$\geq 50$ years & $27 / 151$ & $1.18(0.69$ to 2.03$)$ & 0.54 & $1.43(0.80$ to 1.80$)$ & 0.23 \\
\hline \multicolumn{6}{|l|}{ Nodal status } \\
\hline pNO & $27 / 198$ & 1 & & 1 & \\
\hline $\mathrm{pN}+$ & $23 / 108$ & $1.79(1.02$ to 3.14$)$ & 0.042 & $1.53(0.83$ to 2.85$)$ & 0.18 \\
\hline Missing & $3 / 13$ & - & & - & \\
\hline \multicolumn{6}{|l|}{ Tumor size } \\
\hline$\leq 20 \mathrm{~mm}$ & $28 / 220$ & 1 & & 1 & \\
\hline$>20 \mathrm{~mm}$ & $20 / 79$ & $2.68(1.48$ to 4.83$)$ & 0.001 & $2.31(1.24$ to 4.29$)$ & 0.008 \\
\hline Missing & $5 / 20$ & - & & - & \\
\hline \multicolumn{6}{|l|}{ ER status } \\
\hline Negative & $16 / 68$ & 1 & & & \\
\hline Positive & $21 / 180$ & $0.46(0.24$ to 0.88$)$ & 0.019 & & \\
\hline Missing & $16 / 71$ & - & & & \\
\hline \multicolumn{6}{|l|}{ Inheritance } \\
\hline Maternal & $38 / 229$ & 1 & & 1 & \\
\hline Paternal & $15 / 90$ & $0.99(0.54$ to 1.80$)$ & 0.97 & $0.94(0.48$ to 1.80$)$ & 0.84 \\
\hline
\end{tabular}

CI: Confidence interval; HR: hazard ratio; ER: oestrogen receptor. ${ }^{\dagger}$ Including all the listed variables except ER status due to data missing for 71 patients.

Table II. Recurrence-free survival according to prognostic factors.

\begin{tabular}{|c|c|c|c|c|c|}
\hline \multirow[b]{2}{*}{ Factor } & \multirow[b]{2}{*}{ Events/patients } & \multicolumn{2}{|c|}{ Univariate analysis } & \multicolumn{2}{|c|}{ Multivariate analysis ${ }^{\dagger}$} \\
\hline & & HR $(95 \%$ CI $)$ & $p$-Value & HR $(95 \%$ CI $)$ & $p$-Value \\
\hline \multicolumn{6}{|l|}{ Age } \\
\hline$<50$ years & $50 / 168$ & 1 & & 1 & \\
\hline$\geq 50$ years & $40 / 151$ & $0.84(0.56$ to 1.28$)$ & 0.43 & $0.96(0.61$ to 1.50$)$ & 0.85 \\
\hline \multicolumn{6}{|l|}{ Nodal status } \\
\hline pNO & $49 / 198$ & 1 & & 1 & \\
\hline $\mathrm{pN}+$ & $37 / 108$ & $1.58(1.03$ to 2.43$)$ & 0.035 & $1.40(0.88$ to 2.23$)$ & 0.16 \\
\hline Missing & $4 / 13$ & - & & - & \\
\hline \multicolumn{6}{|l|}{ Tumor size } \\
\hline$\leq 20 \mathrm{~mm}$ & $54 / 220$ & 1 & & 1 & \\
\hline$>20 \mathrm{~mm}$ & $30 / 79$ & 1.97 (1.26 to 3.09$)$ & 0.003 & $1.78(1.11$ to 2.83$)$ & 0.017 \\
\hline Missing & $6 / 20$ & - & & - & \\
\hline \multicolumn{6}{|l|}{ ER status } \\
\hline Negative & $26 / 68$ & 1 & & & \\
\hline Positive & $37 / 180$ & $0.44(0.26$ to 0.72$)$ & 0.001 & - & \\
\hline Missing & $27 / 71$ & - & & & \\
\hline \multicolumn{6}{|l|}{ Inheritance } \\
\hline Maternal & $62 / 229$ & 1 & & 1 & \\
\hline Paternal & $28 / 90$ & $1.22(0.78$ to 1.92$)$ & 0.38 & 1.17 (0.73 to 1.89$)$ & 0.52 \\
\hline
\end{tabular}

CI: Confidence interval; HR: hazard ratio; ER: oestrogen receptor. †'Including all the listed variables except ER status due to data missing for 71 patients.

could be due to a parent-of-origin effect, with increased risk of being affected with maternal-inheritance. That was the conclusion reached by Weinberg et al., who also found a predominance of maternally inherited cases in the large consecutive cohort mentioned above (10). Furthermore, a potential source of bias is due to losses to follow-up. A few patients had migrated during the follow-up period, accordingly, the last date of check-up in the medical record 


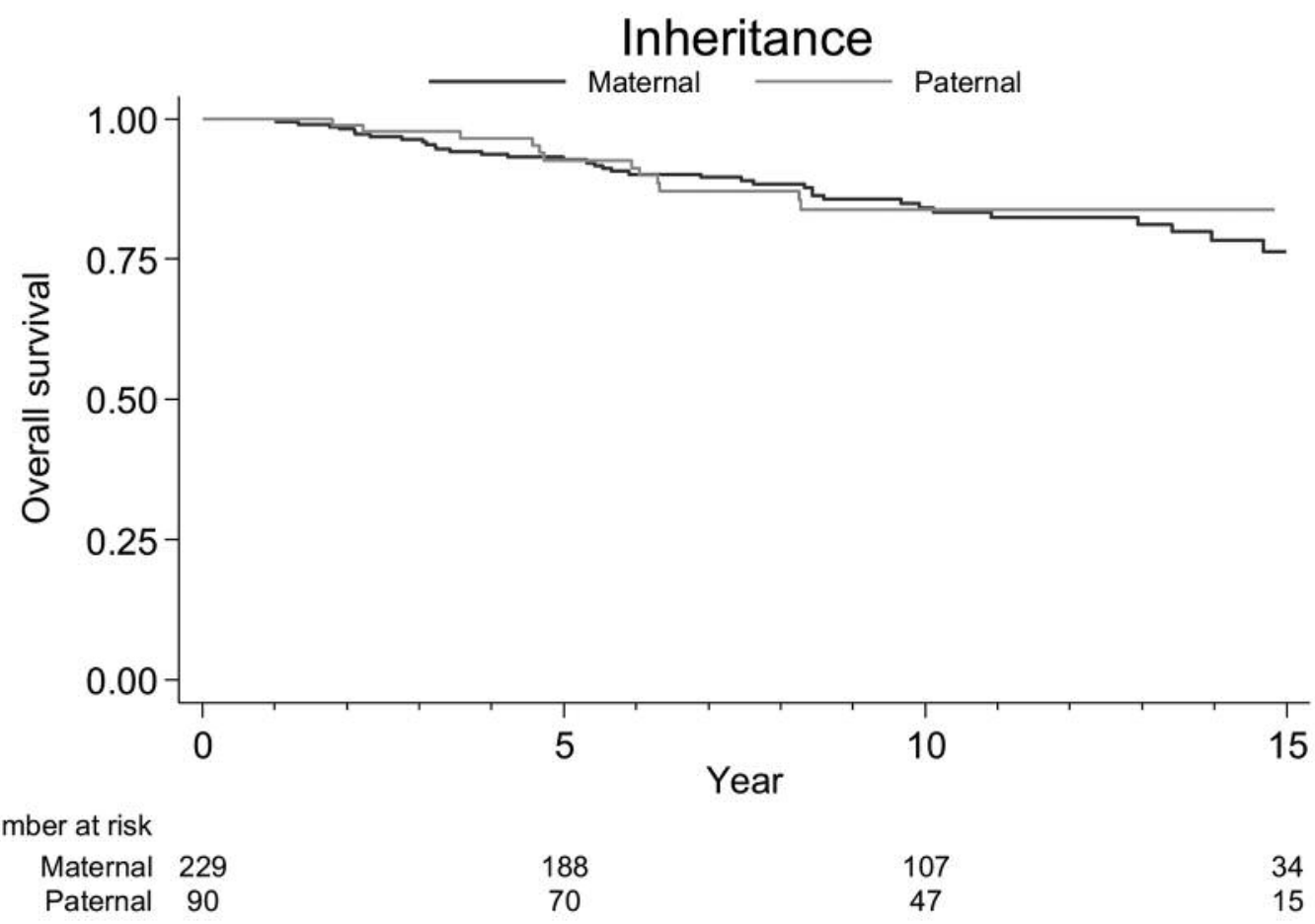

Figure 2. Comparison of survival outcomes for breast cancer patients in the non-BRCA families according to parent of origin of inheritance. BRCA: breast cancer susceptibility genes 1 and 2 .

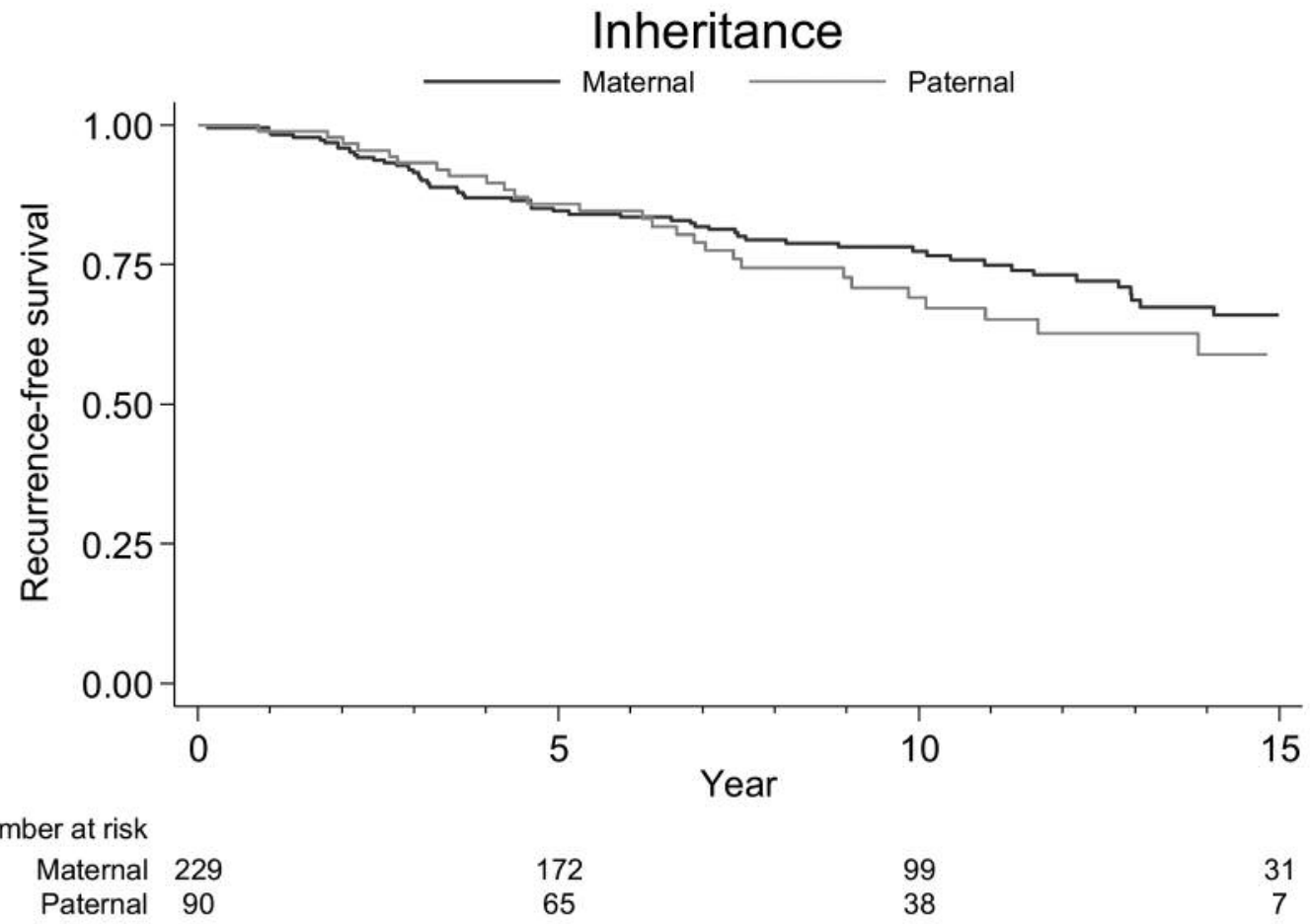

Figure 3. Comparison of recurrence-free survival for patients with breast cancer in the non-BRCA families with parent of origin of inheritance. BRCA: breast cancer susceptibility genes 1 and 2 . 
was used as the date of last visit. We cannot rule out bias due to loss of follow-up but it is less likely since patients were lost randomly. In addition, 24 index patients could not be included at all since no medical records were found.

In summary, we found no evidence for a parent-of-origin effect on breast cancer prognosis in our cohort of non-BRCA families. We consider the result inconclusive but it is unlikely that a great parent-of-origin effect exists. To identify small effects, study of subgroups could be of importance since the epigenetic therapy field is evolving. Furthermore, the asymmetry of the predominance of maternally inherited cases in our cohort indicates that the accuracy of selfreported history is low for patients with paternally inherited breast cancer. This problem could be addressed by encouraging affected women with little knowledge of paternal family history to find out more in order to identify more families at risk that would benefit from preventive programmes. Further research is needed to confirm the discrepancy and identify contributing factors.

\section{Compliance with Ethical Standards}

The study was approved by the Ethics Committee of Karolinska Institute/Karolinska University Hospital, DNR 2012/1453-32, 2011/1686-32 and 2010/1156-31/1.

\section{Competing Interests}

The Authors declare that they have no competing interests in regard to this study.

\section{Acknowledgements}

Financial support was provided through the regional agreement on medical training and clinical research (ALF) between the Stockholm County Council and Karolinska Institute. The Authors are grateful to Hemming Johansson, Christina Bremer and Ulla Platten for valuable assistance.

\section{References}

1 Lindblom A, Rotstein S, Larsson C, Nordenskjold M and Iselius L: Hereditary breast cancer in Sweden: a predominance of maternally inherited cases. Breast Cancer Res Treat 24: 159-165, 1992.

2 Uribe-Lewis S, Woodfine K, Stojic L and Murrell A: Molecular mechanisms of genomic imprinting and clinical implications for cancer. Expert Rev Mol Med 13: e2, 2011.

3 Barrow TM, Barault L, Ellsworth RE, Harris HR, Binder AM, Valente AL, Shriver CD and Michels KB: Aberrant methylation of imprinted genes is associated with negative hormone receptor status in invasive breast cancer. Int J Cancer 137: 537-547, 2015.
4 Radhakrishnan VK, Hernandez LC, Anderson K, Tan Q, De Leon $\mathrm{M}$ and De Leon DD: Expression of intratumoral IGF-II is regulated by the gene imprinting status in triple negative breast cancer from Vietnamese patients. Int J Endocrinol 2015: 401851, 2015.

5 Weischer M, Nordestgaard BG, Pharoah P, Bolla MK, Nevanlinna H, Van't Veer LJ, Garcia-Closas M, Hopper JL, Hall P, Andrulis IL, Devilee P, Fasching PA, Anton-Culver H, Lambrechts D, Hooning M, Cox A, Giles GG, Burwinkel B, Lindblom A, Couch FJ, Mannermaa A, Grenaker Alnaes G, John EM, Dork T, Flyger H, Dunning AM, Wang Q, Muranen TA, van Hien R, Figueroa J, Southey MC, Czene K, Knight JA, Tollenaar RA, Beckmann MW, Ziogas A, Christiaens MR, Collee JM, Reed MW, Severi G, Marme F, Margolin S, Olson JE, Kosma VM, Kristensen VN, Miron A, Bogdanova N, Shah M, Blomqvist C, Broeks A, Sherman M, Phillips KA, Li J, Liu J, Glendon G, Seynaeve C, Ekici AB, Leunen K, Kriege M, Cross SS, Baglietto L, Sohn C, Wang X, Kataja V, Borresen-Dale AL, Meyer A, Easton DF, Schmidt MK and Bojesen SE: CHEK2*1100delC heterozygosity in women with breast cancer associated with early death, breast cancer-specific death, and increased risk of a second breast cancer. J Clin Oncol 30: 4308-4316, 2012.

6 Hartman M, Lindstrom L, Dickman PW, Adami HO, Hall P and Czene K: Is breast cancer prognosis inherited? Breast Cancer Res 9: R39, 2007.

7 Verkooijen HM, Hartman M, Usel M, Benhamou S, NeyroudCaspar I, Czene K, Vlastos G, Chappuis PO, Bouchardy C and Rapiti E: Breast cancer prognosis is inherited independently of patient, tumor and treatment characteristics. Int J Cancer 130: 2103-2110, 2012.

8 Lawson HA, Cheverud JM and Wolf JB: Genomic imprinting and parent-of-origin effects on complex traits. Nat Rev Genet 14: 609-617, 2013.

9 Kong A, Steinthorsdottir V, Masson G, Thorleifsson G, Sulem P, Besenbacher S, Jonasdottir A, Sigurdsson A, Kristinsson KT, Jonasdottir A, Frigge ML, Gylfason A, Olason PI, Gudjonsson SA, Sverrisson S, Stacey SN, Sigurgeirsson B, Benediktsdottir KR, Sigurdsson H, Jonsson T, Benediktsson R, Olafsson JH, Johannsson OT, Hreidarsson AB, Sigurdsson G, Ferguson-Smith AC, Gudbjartsson DF, Thorsteinsdottir $U$ and Stefansson K: Parental origin of sequence variants associated with complex diseases. Nature 462: 868-874, 2009.

10 Weinberg CR, Shi M, DeRoo LA, Taylor JA, Sandler DP and Umbach DM: Asymmetry in family history implicates nonstandard genetic mechanisms: application to the genetics of breast cancer. PLoS Genet 10: e1004174, 2014.

11 Arver B, Claro A, Langerod A, Borresen-Dale AL and Lindblom A: BRCAl screening in patients with a family history of breast or ovarian cancer. Genet Test Mol Biomarkers 3: 223-226, 1999.

12 Chen J, Hedman MZ, Arver BW, Sigurdsson S, Eyfjord JE, and Lindblom A: BRCA2 germline mutations in Swedish breast cancer families. Eur J Hum Genet 6: 134-139, 1998.

Received December 20, 2016

Revised February 8, 2017

Accepted February 13, 2017 